\title{
Idiopathic acute transverse myelitis
}

INSERM

\section{Source}

INSERM. (1999). Orphanet: an online rare disease and orphan drug data base. Idiopathic acute transverse myelitis. ORPHA:139423

Idiopathic acute transverse myelitis (ATM) is an immune-mediated inflammatory demyelinating disorder of the spinal cord with motor, sensory and autonomic involvement. 